\title{
Correlation between C-Peptide Level and Chronic Microvascular Complications in Type 2 Diabetes Mellitus Sudanese Patients
}

\author{
Khalid Mohamed Adam1,2, Shiraz Tajelsir², Deya Aldeen Aowad2 \\ ${ }^{1}$ Faculty of Applied Medical Sciences, Bisha University, Bisha, Kingdom of Saudi Arabia \\ ${ }^{2}$ Department of Clinical Chemistry, Faculty of Laboratory Medical Sciences, Alneelain University, Khartoum, \\ Sudan \\ Email: shirazol200@gmail.com,shirazol_@hotmail.com,dr.aboalbasher@gmail.com
}

Received 5 May 2016; accepted 20 May 2016; published 24 May 2016

Copyright (C) 2016 by authors and OALib.

This work is licensed under the Creative Commons Attribution International License (CC BY). http://creativecommons.org/licenses/by/4.0/

(c) (i) Open Access

\section{Abstract}

Background: C-peptide is a by-product of insulin biosynthesis released in the circulation in amount equimolar with that of insulin; therefore $C$-peptide has been used as an index of insulin secretion and its potential role as a predictor of pancreatic and colorectal cancer and kidney disease have been questioned. The relation between $C$-peptide and diabetic complications attracted the attention of many investigators but not well established yet. The aim of the present study was to explore the relationship between the level of $\mathrm{C}$-peptide and the diabetic microvascular complications in Sudanese patients. Patients and Methods: One hundred and eighty-one type 2 diabetic patients, $61 \%$ males and $39 \%$ females, aged more than 30 years were recruited from different Khartoum hospitals and studied cross-sectionally. Levels of blood C-peptide and HbA1C were measured with commercially available ELISA kit, and the diabetic complications were determined subjectively by experienced physicians. Results: Patients with no complications showed the highest prevalence $33.7 \%$ followed by peripheral neuropathy $33.1 \%$, retinopathy $21.2 \%$ and finally nephropathy $11 \%$. Both no-complications $(9.05 \pm 3.288)$ and retinopathy $(9.10 \pm 3.34)$ groups showed similar level of $C$-peptide, $P$ value $=0.939$. While nephropathy group $(5.50 \pm 3.73)$ and peripheral neuropathy $(6.60 \pm 3.02)$ showed significantly low levels as compared to that of no complication, $P$ value $=0.000$. On the other hand, level of HbA1C showed difference between retinopathy and nephropathy when compared to no complication group but not the peripheral neuropathy. Conclusion: The results of the present study suggest that the most prevalent diabetic complication in Sudanese patients is peripheral neuropathy, and the association between C-peptide and diabetic complications is more prominent with nephropathy and peripheral neuropathy rather than retinopathy.

\section{Keywords}

C-Peptide, Diabetic Complications, Nephropathy, Peripheral Neuropathy, Retinopathy

How to cite this paper: Adam, K.M., Tajelsir, S. and Aowad, D.A. (2016) Correlation between C-Peptide Level and Chronic Microvascular Complications in Type 2 Diabetes Mellitus Sudanese Patients. Open Access Library Journal, 3: e2634. 


\section{Introduction}

Diabetes mellitus is a health problem with socio-economical implications and life-threatening complications. The number of diabetic patients in Africa was estimated to be 14 millions in 2011 and expected to rise to 28 million by 2030 [1]. While in Sudan the prevalence of the disease has risen in four main regions from 9.3\% in 2010 to $10.6 \%$ in 2013 [2] [3]. The prevalence of diabetic complications has also increased in line with the rising occurrence of the disease itself. Despite the significance of chronic diabetic complications as a major cause of morbidity and mortality among diabetic patients, there are few studies with relatively small samples, highlighted theses chronic complications in Africa in general and Sudan in particular [4]. The most common microvascular complications associated with diabetes are, retinopathy, nephropathy, and neuropathy. Retinopathy is believed to be the main cause of blindness among adults in developed countries [5]. In Africa, retinopathy was reported in $16 \%$ - $55 \%$ of diabetic patients [6]. The risk of retinopathy was reported to be associated with duration of the disease and poor glycaemic control [6], a case commonly encountered in Sudan. Nephropathy is one of the most common complications of diabetes; it is the leading cause of end-stage renal disease; diabetic nephropathy is believed to be more frequent among diabetic patients in Africa due to poor disease management and limited diagnostic resources [7]-[9]. Despite the scarcity of published data on complications associated with diabetes in Sudan, the prevalence of nephropathy in Sudanese diabetic patients is believed to be 22\% [10]. It was also reported that there are no substantial differences between patients with type- 1 and type- 2 with respect to the course of diabetic nephropathy in Sudanese [11] although it was presumed that $20 \%$ - 30\% of type- 1 and $10 \%$ $20 \%$ of type-2 patients will develop end-stage renal disease [12] [13]. Diabetic neuropathy is a group of nerve disorders caused by diabetes; this involves various nerves in many body organs, including the feet, arms, heart, digestive system, and urogenital system. Although the rate of complications varies between countries, generally about $60 \%-70 \%$ of diabetic patients develop some form of neuropathy [14]. Nerve problems in diabetic patients can occur at any time; however, the risk increases with age, duration of the disease, blood sugar control, smoking, hypertension, obesity, and hyperlipidemia [14]. Diabetic neuropathy can be classified into four types, namely, peripheral neuropathy, autonomic neuropathy, proximal neuropathy, and focal neuropathy. The most common type of diabetic complications is peripheral neuropathy; for instance in Europe and North America peripheral neuropathy accounts for $28 \%$ - 55\% of all diabetic complications [15]-[17], while in Africa the rate peripheral neuropathy varies between countries ranging from $4 \%$ to $84 \%$ [4]. Although very scarce, the published data on the prevalence of neuropathy in Sudan indicated a $40 \%$ rate among diabetic patients [18]. The diagnosis of diabetes has always relied on blood glucose measurement; however, C-peptide and hemoglobin A1C are proving to be useful tools in the diagnosis of diabetes, hypoglycemia and insulinoma. C-peptide was initially thought to be a by-product of insulin metabolism and biologically inactive; however, its biological activity in relation to diabetes mellitus was emphasized upon by many researchers, and many studies have linked low levels of C-peptide to diabetic complications [19]. C-peptide measurements have also been used as a marker of pancreatic $\beta$-cell function. C-peptide is produced by the enzymatic cleavage of preproinsulin and proinsulin that are produced in the pancreatic $\beta$-cells in response to elevated blood glucose, the enzymatic cleavage of proinsulin by proconvertase and carboxypeptidase yields insulin and C-peptide, which are released in equimolar amounts from $\beta$-cells into the portal circulation. C-peptide is cleared by the kidneys and has a half-life of about 20 to 30 minutes compared to insulin which is cleared by the liver and has a half-life of about 3 to 5 minutes [20]. On the other hand, hemoglobin A1c (HbA1c) reflects the average level of glucose in the blood over a period of 2 - 3 months by measuring the proportion of hemoglobin that has become glycosylated. The aim of this study was to investigate how blood C-peptide and HbA1C relate to the risk of retinopathy, nephropathy and peripheral neuropathy in Sudanese diabetes mellitus patients.

\section{Materials and Methods}

A cross-sectional study included 181 patients suffered diabetes mellitus type 2 for at least 3 years, and aged more than 30 years, recruited from Jaber Abo Elez hospital, Zenam center for diabetes and hemodialysis, and 
Mohamed Ali Altoum diabetes center, during the period from 2015-2016. Patients' clinical information included duration of the disease, history of hypertension and familial history of diabetes were obtained from their respective medical records. Patients with chronic disease, active infection, and alcoholism were excluded. Diabetic complications of the participants were evaluated subjectively by experienced physicians or by referring to their respective medical records. Retinopathy was evaluated by experienced ophthalmologist, cases that required retinal photography and fundoscopic examination was carried out. Peripheral neuropathy was evaluated by quantitative sensory testing by assessing touch, vibration and heat conducted by experienced neurologist. Diabetic nephropathy was evaluated by measuring urinary albumin concentration at random, $17 \mathrm{~m} / \mathrm{l}$ was set as the cut off point for diagnosis of microalbuminuria [21]. Serum C-peptide levels were measured by Human C-peptide EIA kit (Raybiotech-USA) with detection range of $0.1-1000 \mathrm{ng} / \mathrm{ml}$, All reagents, buffers and controls were prepared as per the manufacturer instructions, $100 \mu \mathrm{l}$ of anti c-peptide was added to each well incubated for 1.5 hour at room temperature (R.T), then $100 \mu \mathrm{l}$ of each sample and standard were added to their designated wells and then incubated for 2.5 hour at R.T, followed by adding $100 \mu \mathrm{l}$ of streptavidin to each well and incubated for 45 minutes at R.T and then $100 \mu \mathrm{l}$ of the substrate was added to each well and incubated for 30 minutes at R.T, then $50 \mu \mathrm{l}$ of the stop solution was added and the plates were read immediately at $450 \mathrm{~nm}$. Glycated hemoglobin (HbA1C) was measured by Hemoglobin A1C-Direcr (HbA1C-DIR) (BioSystems-Spain) as per the manufacturer's instructions and the sample was read twice at $670 \mathrm{~nm}$ after 10 seconds and 5 minutes of incubation. This study was approved by the ethical committee of faculty of medical laboratory sciences, Alneelain University, and an informed oral consent was obtained from all participants prior to specimen collection. The results of the study were made available for participants.

\section{Statistical Analysis}

Data were analyzed with IBM SPSS statistics 20, and expressed as Mean \pm SD. Level of significance was set at $<0.05$. T test and ANOVA tests were used to compare C-peptide and HbA1C in different groups, and Pearson correlation was used to assess the associations between different study variables.

\section{Results}

The present study comprised of 181 type 2 diabetic patients, 61\% male and 39\% female, with age range 39 - 80 (Mean $60.04 \pm 10.022)$ and disease duration 3 - 40 year (12.50 \pm 5.5 ), 21\% hypertensive and 79\% normotensive. Patients were assigned to four groups based on the type of the diabetic complications, $33.7 \%$ no complications, $21.2 \%$ retinopathy, $11 \%$ nephropathy, and 33.1\% peripheral neuropathy. The level of C-peptide of diabetic patients with no complications $(9.05 \pm 3.28)$ showed no significant difference when compared with that of diabetic patients with retinopathy $(9.10 \pm 3.34)$ with $\mathrm{P}$ value 0.939 , however, significant difference was seen when compared with nephropathy group (5.50 \pm 3.73 ) with $\mathrm{P}$ value 0.000 , and with peripheral neuropathy group (6.60 \pm 3.02) with $\mathrm{P}$ value 0.000 . On the other hand the comparison of the HbA1C in the three groups with complications with the no complication group showed a significant difference between the no complication group and both retinopathy group with $\mathrm{P}$ value 0.001 , and nephropathy group with $\mathrm{P}$ value 0.040 , but not with peripheral neuropathy group, $\mathrm{P}$ value 0.482 , as shown in Table 1 . Comparison of the diabetic complications based on the duration of diabetes showed that those with no complications had the least duration $(10.74 \pm 7.1)$ followed by those with retinopathy $(11.75 \pm 5.01)$ and those with nephropathy $(14.10 \pm 2.26)$ and those with peripheral neuropathy (14.27 \pm 3.77$)$, as shown in Figure 1. The correlation results showed no correlation between C-peptide level and HbA1C, P value 0.262, similar results were also seen between C-peptide level and age at diagnosis, P value 0.06 and duration of the disease, $\mathrm{P}$ value 0.05 , as shown in Table 2 . When the level of $\mathrm{C}$-peptide was compared between smokers and non-smokers, and between hypertensive and normotensive, no significant difference was observed in neither of the two cases, with $\mathrm{P}$ value 0.887 and 0.083 respectively. Similar results were also obtained when C-peptide was compared based on the gender of the patient, with P value 0.933 , as shown in Table 3.

\section{Discussion}

Diabetic angiopathies are believed to be the major complications related to diabetes mellitus, number of studies have suggested a strong association between microvascular complications and poor glycemic control [22] [23]. 


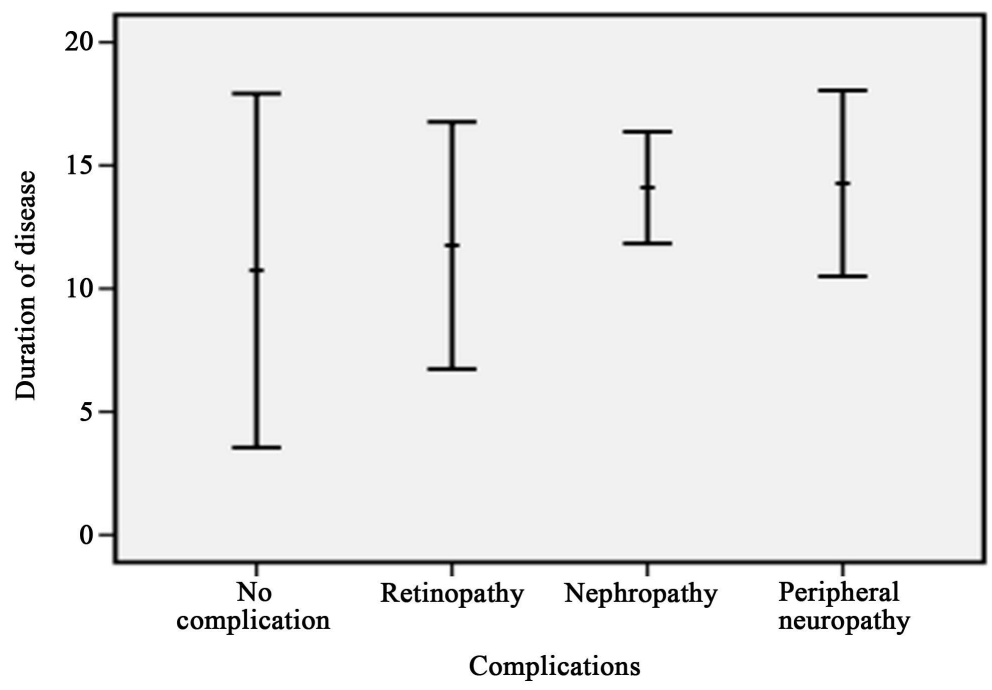

Figure 1. Diabetic complications according to the duration of the disease.

Table 1. ANOVA test for C-peptide and HbA1C in the study groups.

\begin{tabular}{ccccccccc}
\hline & & \multicolumn{2}{c}{ Retinopathy } & \multicolumn{2}{c}{ Nephropathy } & \multicolumn{2}{c}{ Peripheral neuropathy } \\
\hline \multirow{2}{*}{ C-peptide $^{*}$} & \multirow{2}{*}{ No complication $(9.05 \pm 3.288)$} & Mean \pm SD & Sig & Mean \pm SD & Sig. & Mean \pm SD & Sig. \\
\cline { 3 - 8 } & & $(9.10 \pm 3.34)$ & 0.939 & $(5.50 \pm 3.73)$ & 0.000 & $(6.60 \pm 3.02)$ & 0.000 \\
\hline HbA1C $^{*}$ & \multirow{2}{*}{ No complication $(8.28 \pm 1.854)$} & $(9.55 \pm 2.34)$ & 0.001 & $(9.30 \pm 1.94)$ & 0.040 & $(8.03 \pm 1.63)$ & 0.482 \\
\hline
\end{tabular}

Table 2. Correlation between C-peptide, HbA1C, disease duration and age.

\begin{tabular}{ccccc}
\hline & & Hb A1c & Duration of disease & Age \\
\hline \multirow{3}{*}{ C-peptide } & $\mathbf{r}$ & -0.084 & -0.145 & -0.140 \\
& Sig. & 0.282 & 0.051 & 0.061 \\
& $\mathbf{N}$ & 181 & 181 & 181 \\
\hline
\end{tabular}

Table 3. Comparison of C-peptide according to smoking, hypertension and gender.

\begin{tabular}{cccccc}
\hline & $\mathbf{N}$ & Mean \pm SD & Std. error & P value \\
\hline Smokers & 78 & $11.00 \pm 2.51$ & 0.535 & 0.887 \\
Non-smokers & 103 & $10.71 \pm 3.53$ & 0.268 & 0.605 \\
C-peptide & Hypertensive & 38 & $8.79 \pm 3.72$ & 0.288 & 0.083 \\
& Normotensive & 143 & $7.61 \pm 3.44$ & 0.339 & 0.933 \\
\hline
\end{tabular}

The level of blood C-peptide as an appropriate measure of insulin secretion was previously reported, although it was first believed that C-peptide is an inactive by-product of insulin metabolism, recent reports are suggestive of hormonal activity of this molecule [24]-[26]. Number of studies have reported an association between C-peptide and the risk of pancreatic and colorectal cancer [27] [28]. C-peptide level was also investigated as predictor for cardiovascular disease in non-diabetic adults [29]. In the current study we explored the association between the non-fasting C-peptide level and the diabetic complications. The findings of the present study showed that the 
most prevalent diabetic complication is peripheral neuropathy, followed by retinopathy and the nephropathy, this is supported by results from a previous study carried out on Sudanese diabetic patients [30] and it is worth noting that the percentages of diabetic complications in this study fall well within the range of prevalence in Africa. Both no-complications group and retinopathy group showed a significantly higher C-peptide level than nephropathy group and peripheral neuropathy group, which disagree with previously reported results [22], while other studies reported a protective effect of high C-peptide level [31]-[34] which indicates low levels of C-peptide in those with diabetic complications. The C-peptide level in the present study showed no correlation with the duration of the disease, although patients with no complications were of lower disease duration when compared to the other three groups, a similar result was also reported [22] [35], and the fact that diabetic complications require long time to appear may explain the difference in the disease duration between those with no complications and those with complications. In the present study both retinopathy and nephropathy groups showed higher level of $\mathrm{Hb}$ A1C comparatively to the no complication group, this goes in concordance with previous reports [4] [7] [10], while the result of the peripheral neuropathy group show no difference from the no complication group which contradict earlier results [10] that reported an association between increased Hb A1C and different neuropathies, this may be attributed to the difference in the study design and population. Neither the results of comparison based on smoking, nor based on hypertension showed difference in the level of C-peptide between the compared groups, similar results were reported for both diabetics and non-diabetics [28] [36].

\section{Conclusion}

The present study is one of the few attempts to explore the relation between C-peptide and diabetic complications in Sudanese type 2 DM patients. The results indicate that peripheral neuropathy is the most prevalent complication followed by retinopathy and nephropathy. It can also be concluded that there is an association between low level of C-peptide and nephropathy and peripheral neuropathy but not retinopathy. The results also suggest that $\mathrm{HbA1C}$, duration of the disease, age and gender of the patient, smoking habit and high blood pressure have no influence over the level of C-peptide in Sudanese diabetic patients.

\section{Acknowledgements}

We are highly indebted to all the staff of Jaber Abo Elez hospital, Zenam center for diabetes and hemodialysis, and Mohamed Ali Altoum diabetes center for their cooperation and help. Our gratitude is to staff of department of clinical chemistry, faculty of medical lab. Sciences-Alneelain University.

\section{References}

[1] International Diabetes Federation (2011) IDF Diabetes Atlas. 5th Edition, International Diabetes Federation, Brussels.

[2] Balla, S.A., Abdalla, A.A., Elmukashfi, T.A. and Ahmed, H.A. (2014) Hypertension among Rural Population in Four States: Sudan 2012. Global Journal of Health Science, 6, 206. http://dx.doi.org/10.5539/gjhs.v6n3p206

[3] Muninarayana, C., Balachandra, G., Hiremath, S., Iyengar, K. and Anil, N. (2010) Prevalence and Awareness Regarding Diabetes Mellitus in Rural Tamaka, Kolar. International Journal of Diabetes in Developing Countries, 30, 18. http://dx.doi.org/10.4103/0973-3930.60005

[4] Tesfaye, S. and Gill, G. (2011) Chronic Diabetes Complications in Africa. African Journal of Diabetes Medicine, 19.

[5] Frank, R. (2004) Diabetic Retinopathy. New England Journal of Medicine, 350, 48-58. http://dx.doi.org/10.1056/NEJMra021678

[6] Mbanya, J.C. and Sobngwi, E. (2003) Diabetes in Africa. Diabetes Microvascular and Macrovascular Disease in Africa. Journal of Cardiovascular Risk, 2, 97-102. http://dx.doi.org/10.1177/174182670301000204

[7] Noubiap, J.J.N., Naidoo, J. and Kengne, A.P. (2015) Diabetic Nephropathy in Africa: A Systematic Review. World Journal of Diabetes, 6, 759-773. http://dx.doi.org/10.4239/wjd.v6.i5.759

[8] Kengne, A.P., Sobngwi, E., Echouffo-Tcheugui, J.B. and Mbanya, J.C. (2013) New Insights on Diabetes Mellitus and Obesity in Africa-Part 2: Prevention, Screening and Economic Burden. Heart, 99, 1072-1077. http://dx.doi.org/10.1136/heartjnl-2013-303773

[9] Mbanya, J.C., Motala, A.A., Sobngwi, E., Assah, F.K. and Enoru, S.T. (2010) Diabetes in Sub-Saharan Africa. Lancet, 375, 2254-2266. http://dx.doi.org/10.1016/S0140-6736(10)60550-8 
[10] Fahal, I.H. (2009) The Diabetic Kidney_-“A Systematic, Diabetes Renal Service, Better for Patients and Clinicians”. Sudan Medical Journal, 45.

[11] Parving, H.-H. (1996) Initiation and Progression of Diabetic Nephropathy. New England Journal of Medicine, 335, 1682-1683. http://dx.doi.org/10.1056/NEJM199611283352212

[12] Andersen, A.R., Sandahl Christiansen, J., Andersen, J.K., Kreiner, S. and Deckert, T. (1983) Diabetic Nephropathy in Type-1 (Insulin-Dependent) Diabetes: An Epidemiological Study. Diabetologia, 25, 496-501. http://dx.doi.org/10.1007/BF00284458

[13] DeFronzo, R.A. (1995) Diabetic Nephropathy: Etiologic and Therapeutic Considerations. Diabetes Reviews, 3, 510564.

[14] Razmaria, A.A. (2015) Diabetic Neuropathy. JAMA, 314, 2202. http://dx.doi.org/10.1001/jama.2015.15899

[15] Tesfaye, S., Stevens, L., Stephenson, J., et al., on Behalf of the EURODIAB IDDM Study Group (1996) The Prevalence of Diabetic Neuropathy and Its Relation to Glycaemic Control and Potential Risk Factors: The EURODIAB IDDM Complications Study. Diabetologia, 39, 1377-1384. http://dx.doi.org/10.1007/s001250050586

[16] Boulton, A.J., Malik, R.A., Arezzo, J.C. and Sosenko, J.M. (2004) Diabetic Somatic Neuropathies. Diabetes Care, 27, 1458-1486. http://dx.doi.org/10.2337/diacare.27.6.1458

[17] Dyck, P.J., Kratz, K.M., Karnes, J.L., et al. (1993) The Prevalence by Staged Severity of Various Types of Diabetic Neuropathy, Retinopathy, and Nephropathy in a Population-Based Cohort: The Rochester Diabetic Neuropathy Study. Neurology, 43, 817-824. http://dx.doi.org/10.1212/WNL.43.4.817

[18] Bos, M. and Agyemang, C. (2013) Prevalence and Complications of Diabetes Mellitus in Northern Africa, a Systematic Review. BMC Public Health, 13, 387. http://dx.doi.org/10.1186/1471-2458-13-387

[19] Palmer, J.P., Fleming, G.A., Greenbaum, C.J., et al. (2004) C-Peptide Is the Appropriate Outcome Measure for Type 1 Diabetes Clinical Trials to Preserve Beta-Cell Function: Report of an ADA Workshop, 21-22 October 2001. Diabetes, 53, 250-264.

[20] Marques, R.G., Fontaine, M.J. and Rogers, J. (2004) C-Peptide: Much More than a Byproduct of Insulin Biosynthesis. Pancreas, 29, 231-238. http://dx.doi.org/10.1097/00006676-200410000-00009

[21] Gross, J.L., de Azevedo, M.J., Silveiro, S.P., Canani, L.H., Caramori, M.L. and Zelmanovitz, T. (2005) Diabetic Nephropathy: Diagnosis, Prevention, and Treatment. Diabetes Care, 28, 164-176.

[22] Sari, R. and Balci, M.K. (2005) Relationship between C Peptide and Chronic Complications in Type-2 Diabetes Mellitus. Journal of the National Medical Association, 97, 1113-1118.

[23] Lev-Ran, A., Hwang, D., Barseghian, G. and Hill, L.R. (1986) Control of Noninsulin Dependent Diabetes Is Not Correlated with Endogenous Insulin Secretion. Diabetes \& Metabolism, 12, 325-328.

[24] Johansson, J., Ekberg, K., Shafqat, J., et al. (2002) Molecular Effects of Proinsulin C-Peptide. Biochemical and Biophysical Research Communications, 295, 1035-1040. http://dx.doi.org/10.1016/S0006-291X(02)00721-0

[25] Hills, C.E., Brunskill, N.J. and Squires, P.E. (2010) C-Peptide as a Therapeutic Tool in Diabetic Nephropathy. American Journal of Nephrology, 31, 389-397. http://dx.doi.org/10.1159/000289864

[26] Mughal, R.S., Scragg, J.L., Lister, P., et al. (2010) Cellular Mechanisms by Which Proinsulin C-Peptide Prevents Insulin-Induced Neointima Formation in Human Saphenous Vein. Diabetologia, 53, 1761-1771. http://dx.doi.org/10.1007/s00125-010-1736-6

[27] Michaud, D.S., Wolpin, B., Giovannucci, E., Liu, S., Cochrane, B., Manson, J.E., Pollak, M.N., Ma, J. and Fuchs, C.S. (2007) Prediagnostic Plasma C-Peptide and Pancreatic Cancer Risk in Men and Women. Cancer Epidemiology, Biomarkers \& Prevention, 16, 2101. http://dx.doi.org/10.1158/1055-9965.EPI-07-0182

[28] Ma, J., Giovannucci, E., Pollak, M., Leavitt, A., Tao, Y., Gaziano, J.M. and Stampfer, M.J. (2004) A Prospective Study of Plasma C-Peptide and Colorectal Cancer Risk in Men. Journal of the National Cancer Institute, 96, 546-553. http://dx.doi.org/10.1093/jnci/djh082

[29] Patel, N., Taveira, T.H., Choudhary, G., Whitlatch, H. and Wu, W.-C. (2012) Fasting Serum C-Peptide Levels Predict Cardiovascular and Overall Death in Nondiabetic Adults. Journal of the American Heart Association, 1, e003152. http://dx.doi.org/10.1161/jaha.112.003152

[30] Elmahdi, E.M., Kaballo, A.M. and Mukhtar, E.A. (1991) Features of Non-Insulin-Dependent Diabetes Mellitus (NIDDM) in the Sudan. Diabetes Research and Clinical Practice, 11, 59-63. http://dx.doi.org/10.1016/0168-8227(91)90142-Z

[31] Mosier, M.A. (1984) Circulating C Peptide and Diabetic Retinopathy. Diabetes Research, 1, 151-154.

[32] Suzuki, K., Watanabe, K., Motegi, T. and Kajinuma, H. (1989) High Prevalence of Proliferative Retinopathy in Diabetic Patients with Low Pancreatic B-Cell Capacity. Diabetes Research and Clinical Practice, 6, 45-52. http://dx.doi.org/10.1016/0168-8227(89)90056-9 
[33] Inukai, T., Matsutoma, R., Tayama, K., Aso, Y. and Takemura, Y. (1999) Relation between the Serum Level of C Peptide and Risk Factors for Coronary Heart Disease and Diabetic Microangiopathy in Patients with Type-2 Diabetes Mellitus. Experimental and Clinical Endocrinology \& Diabetes, 107, 40-45. http://dx.doi.org/10.1055/s-0029-1212071

[34] Madsbad, S., Laurtzen, E., Faber, O.K. and Binder, C. (1986) The Effect of Residual Beta-Cell Function on the Development of Diabetic Retinopathy. Diabetic Medicine, 3, 42-45. http://dx.doi.org/10.1111/j.1464-5491.1986.tb00704.x

[35] Kim, B.-Y., Jung, C.-H., Mok, J.-O., Kang, S.-K. and Kim, C.-H. (2012) Association between Serum C-Peptide Levels and Chronic Microvascular Complications in Korean Type 2 Diabetic Patients. Acta Diabetologica, 49, 9-15. http://dx.doi.org/10.1007/s00592-010-0249-6

[36] Nilsson, P., Lundgren, H., Söderström, M., Fagerström, K.O. and Nilsson-Ehle, P. (1996) Effects of Smoking Cessation on Insulin and Cardiovascular Risk Factors-A Controlled Study of 4 Months' Duration. Journal of Internal Medicine, 240, 189-194. http://dx.doi.org/10.1046/j.1365-2796.1996.16844000.x 